\title{
Who creates the Bandwagon? The dynamics of fear of isolation, opinion congruency and anonymity-efficacy on social media in the 2017 South Korean presidential election
}

\begin{abstract}
This study proposes a new approach to fear of isolation (FOI) with special attention to psychological motivations/gratifications sought in the online sphere (opinion congruencyseeking and anonymity-efficacy), which may lead to political expression via social media. We posit that individuals with FOI will display a tendency to want to match their opinions with the majority and will also actively utilize online platforms as they offer anonymity. This empirical study collected data from a random sample of 1,107 participants in South Korea, a frontrunner in terms of political expression on social media. The results demonstrated that FOI is associated with opinion congruency as well as anonymity-efficacy and further, political use of social media which in turn prompts offline political engagement. Findings of this paper contributes to a better understanding of users' willingness for political expression and how active participation on social media lead to the creation of bandwagons both online and off. (150 words)
\end{abstract}

Keywords: Fear of isolation, opinion congruency, bandwagon effect, social media, political expression, political engagement, social media

\author{
KyuJin Shim, Ph.D \\ Assistant Professor of Corporate Communication \\ Lee Kong Chian School of Business \\ Singapore Management University \\ 50 Stamford Road 178899 Singapore \\ +65-9661-0275 \\ q.kyujinshim@gmail.com
}

and
Soo-Kwang (Klive) Oh, Ph.D*
Assistant Professor
Communication Division
Pepperdine University
24255 Pacific Coast Highway
Malibu, CA 90263
+1 310-506-4211
kliveoh@gmail.com

*Corresponding Author 


\title{
Who creates the Bandwagon? The dynamics of fear of isolation, opinion congruency and anonymity-efficacy on social media in the 2017 South Korean presidential election
}

\begin{abstract}
This study proposes a new approach to fear of isolation (FOI) with special attention to psychological motivations/gratifications sought in the online sphere (opinion congruencyseeking and anonymity-efficacy), which may lead to political expression via social media. We posit that individuals with FOI will display a tendency to want to match their opinions with the majority and will also actively utilize online platforms as they offer anonymity. This empirical study collected data from a random sample of 1,107 participants in South Korea, a frontrunner in terms of political expression on social media. The results demonstrated that FOI is associated with opinion congruency as well as anonymity-efficacy and further, political use of social media which in turn prompts offline political engagement. Findings of this paper contributes to a better understanding of users' willingness for political expression and how active participation on social media lead to the creation of bandwagons both online and off. (150 words)
\end{abstract}

Keywords: Fear of isolation, opinion congruency, bandwagon effect, social media, political expression, political engagement, social media 
Social media have become effective political vehicles, not only for politicians to mobilize support for successful campaigns, but also for citizen-centered engagement for their own political disinhibition. For example, throughout recent political events in South Korea including a public uprising against the corruption scandal of the incumbent government and the subsequent liberal counterpart's winning the presidency, social media played a significant role for citizens in displaying their anger as well as to take actions against the status quo.

In political campaigning, social media's importance is not a new idea. Scholarly and mass media sources alike have pointed out Barack Obama's and/or Donald Trump's successes in the two most recent U.S. presidential elections (Enli, 2017; Kreiss, 2016; Morin, 2016; Pramuk, 2016; Vargo, Guo, McCombs, \& Shaw, 2014). Moreover, the literature increasingly has emphasized the electoral influence of social media, on topics such as the changing nature of public discourse (McKinnon, Semmens, Moon, Amarasekara, \& Bolliet, 2016; Ott, 2017) and public perceptions of politicians (Chen \& Chang, 2017; Lee \& Shin, 2014).

However, we note that existing work on social media and political campaigns focuses on politicians' social media usage. We argue that the two-way, interactive nature of social media warrants research of the other side of political campaigns, namely users and voters. How do voters use social media for their political engagement and participation? This is an increasingly-significant question as the general public have become empowered (Jensen, 2017) and, through their social media activities, have the potential to affect the favorability of political candidates, thus election outcomes (Wang \& Yue, 2016). In South Korea's recent political events involving the Park Geun-hye corruption scandal, record-breaking candlelight vigil protests, Park's impeachment, and eventual election of Moon Jae-in, citizens utilized social media on scales augmenting each step of the process (Campbell, 2017; Lim, 2016). 
Moon's victory is said to mark the triumph of ordinary people who, more important, made this liberal party candidate into the continually-leading candidate, unlike previous instances of underdog liberal candidates (for example, Moon's strong supporting groups are rooted in regaining the post-mortem popularity of the late President Roh Moo-hyun after his May 2009 death, who in the conservative Korean political landscape, had been considered a perpetual underdog) (Choe, 2017; Lim, 2016).

We believe what social media does for political change is more citizen-centric than elite-oriented. To us, that seems the stellar example of an ordinary people - who otherwise would have been silent under the sheer pressure of the political majority — creating and actually successfully using the great political utility of social media. Moon is the first president considered as Mr. Favorite of the Supporters, rather than Mr. Charismatic Leader Himself. His supporter groups are well known not only for their strong fandom and loyalty, but also for their strong ties among each other online comparable to fan communities or even hooligans of football teams (D. Kim, 2017; Oh, 2017). Moon's following on social media shows remarkable strength in both numbers and loyalty (D. Kim, 2017; Oh, 2017). Mostly with success, Moon continues to be active on social media even after his inauguration (Chung, 2017). Throughout the entire election process, he never lost his lead in the polls, his strong online following tended to create a bandwagon effect making him questionably (and invariably) the top candidate. His success is arguably in a different political context from that of the late President Roh Moo-hyun, who led the same liberal party as did and does Moon.

Based on clear overlap between Moon's supporters' massive online presence and actual voting turnout that successfully brought about the regime change, we believe citizens as constituents not only voice their opinions via social media, but also further establish political movements via concerted political engagement and participation. 
In this study, we examine the mechanism through which an individual's political engagement and participation on social media may be driven by the nature of online such as anonymity and/or subsequent selectivity and vice versa. First, the bandwagon effect in political campaign would be created by those who engage strongly and hold strong opinioncongruency (e.g., partisans). They tend to seek selective online platforms enabling users to speak free of any sanctions or penalty that could be possibly impose on their real-life political engagement, as their strong opinions potentially could harm their real-life reputations or relationship with those who are politically opposite or different.

Also, in Asian culture that values harmony with others of different opinions, anonymous and selective platforms are driving new political forces. In the Japanese examples of extreme and polarized web communities such as 2 Channel, Zaitokukai or Netto-uyo and, Ilbe (Daily Best) or Today's Humor of Korea, users pursue "absolute freedom of speech" and extreme political partisanship whether liberal or conservative. This participation leads to strong engagement on social media platforms such as Facebook or Twitter. Furthermore, users even populate news conversation threads in major portal news sites such as Naver and Daum by using secondary IDs or pseudonyms to separate their selective online engagement from their real-life identities. Here, anonymity seems to play a key role.

South Koreans' and other East-Asian cultures' anonymity preference for political disinhibition and freedom of speech have been studied previously (MacKinnon, 2008; Oh, 2016; Udris, 2014). Thus, we believe under social pressure, people in a high level of opinion congruence would feel more fear of isolation thus tend to seek online anonymity in pursuing freedom of speech for political disinhibition and expression.

To examine this, we propose three key variables that may lead to social media engagement for political engagement: opinion congruency, anonymity preferences, and fear of isolation. A quota sample $(\mathrm{N}=1107)$ has been collected during the Primary for the 2017 
South Korean presidential election and we examine the relationship and effects of the above for an individual's political participation on social media. We posit that individuals strongly desiring to align their opinions with those of the majority and elites in society actively will use online platforms because 1) they want to seek like-minded voters and 2) they prefer anonymous environments for constraint-free political conversations. We also hypothesize that one's fear of being isolated will be a significant underlying factor behind the above process.

We believe this study explores a new framework of political psychology that goes beyond conventional paradigms (e.g., selective exposure based on partisanship or ideology) and that this study contributes to better understanding of anonymous and online behaviors in generating political engagement.

\section{Literature Review}

\section{Fear of Isolation, opinion congruency and anonymity-preference}

Fear of isolation (FOI) can be defined as a "psychological variable representing a negative emotional state associated with the prospect of voicing one's opinion about a given topic.” (Neuwirth, Frederick, \& Mayo, 2007, p. 452). FOI closely associates with public opinion or one's perceptions of it, in that others as groups disagree with an individual's opinion on the topic matter (Noelle-Neumann, 1974). As Neuwirth et al (2007) also point out, communication apprehension (CA) theory is applicable to FOI; perceived disagreement of a self's opinions with a group's may cause "fear or anxiety associated with either real or anticipated communication with a person or persons" (pp.452-453).

Existing studies mostly link FOI with the so-called Spiral of Silence, meaning FOI would lead to silence or to conformity with the perceived dominant opinion. Yet, the impact of FOI has been found beyond the generation of silence. For example, Hayes, Mattes, and Eveland (2011) have suggested that "Fear of social isolation does appear to motivate people to ascertain what the public thinks" (p. 1). They have found "those who fear social isolation 
to a greater extent are more likely to attend to a particular source of information in the social environment about public opinion—mass media reports of public opinion polls" (p.1). Based on this finding, it is conjectured that people under FOI quest for knowledge of the opinion climate, extensive by media use. So, it is noted that FOI rather prompts media use due to the "need to belong" motivation, thus leads to the selective participation and engagement where they themselves can be drivers of their own bandwagon (new paradigm of bandwagon creation) where people want to act as if they belong to a majority group of public opinion.

Even in the online environment, arguments linking FOI to Spiral of Silence have been made - according to Gearhart and Zhang (2015), encountering agreeable political content is a predictor for the willingness to speak out, while disagreeable postings hinder opinion expression. In fact, findings on people's inclinations for selective posting (Porten-Cheé \& Eilders, 2015; Yun \& Park, 2011) imply that online participation increases because people look for psychological and political homogeneity. Further, FOI may prompt individuals to seek information about the climate of public opinion (Hayes et al., 2011; S.-H. Kim, Kim, \& Oh, 2014).

\section{Opinion congruency seeking and online participation}

Opinion congruency can be defined in terms of political psychology such as need to belong motivation and/or high level of selectivity where people want to coincide their own opinions with the majority and/or other opinion leaders. Thus, opinion congruency can be connected to quest for knowledge as they want to monitor what the major opinion is. More, opinion congruency needs might encourage online participation, as those who want their opinions to match those of others might hold or pursue de facto online leadership to align their own opinions on an issue or a political candidate with the dominant opinion among the community (Lampel \& Bhalla, 2007). We argue that informational gift-giving is also strongly driven by status-seeking, and that status sentiments are more likely to sustain virtual 
communities. For example, Bobkowski (2015) examined personality traits on online news sharing: opinion leaders proactively share news deemed valuable information. Therefore, we can posit that opinion congruency-seeking might trigger online users' active informationsharing and political engagements. It is presumed that FOI would be associated with the need to be a part of a partisan community who share common political ideologies; thereby one easily draws attention or status from peers in the group through excessive and enthusiastic politics-based knowledge attainment and conversation. Clear is that "the influence of opinion climates was greater among those who had a greater fear of isolation in general" (S.-H. Kim, 2012, p.306). Also, it was found that people with substantial motivation to belong to a group would seek congruency on important social issues (Morrison \& Matthes, 2011).

\section{Online preference for political homogeneity}

Long a scholarly debate is whether new media as an alternative news outlet potentially could secure freedom of speech, thereby contribute to voicing and interacting diverse views on any sensitive political issue via exposure to "cross-cutting" political opinions (e.g., Brundidge, 2010). We note that selective exposure and partisan media might not be a new concept, particularly in lieu of online alternatives. Rather ironic is that new media started to be favored in reaction to the alleged partisanship of mainstream news outlets such as Fox News and its increasing popularity in the US media market (Iyengar \& Hahn, 2009). This notion might be related to hostile media effect meaning that partisans attribute bias to mainstream news outlets, but in fact tend to evaluate media as biased due to their own inherent bias and political views, instead of the media frame itself being biased (Feldman, 2011). Also, it was found that those who perceive traditional media bias tend to attend alternative sources deeming them as less biased and more objective, thus congenial to their preferences. 
However, if it is the case where online use contributes to political heterogeneity, it is considered to be due mainly to online "inadvertency" (Brundidge, 2010). More, ample studies weigh on the effect of motivated political homogeneity of online rather than inadvertent political diversity (e.g., Iyengar \& Hahn, 2009; Hahn, Ryu \& Park, 2015). More, we look at the value of online as a selective platform compatible for political homogeneity. Many studies pointed out online media bias and its selective use and political ideology (Baum \& Grueling, 2008; Meyer, Marchionni \&Thorson, 2010). This political selectivity of online indicates that online users easily seek opinion congruency, which further suggests the prompting of online attendance. To be specific, Baum and Grueling (2008) aver that partisanship filtering is greater for online news sources than for traditional news wires. They found that traditional news wires rely on newsworthiness while online news sources care for partisan interest. Likewise, the Meyer et al. (2010) experiment result indicated that in online context, if an individual audience feels more sense of kinship or co-orientation with the author or message sender, he or she is likely to perceive the content as more credible.

As for the advent of partisan media regarding the rise of new media platform, we also note the important role of podcast as a cutting-edge political platform by generating emotional engagement in politics. For example, during the 2012 South Korean Presidential campaign, partisan podcasts played an important role in building images of, and emotions toward, candidates (Kim, Kim \& Wang, 2016). The study underpins the role of podcastgenerated "emotion" subsequently-triggering political participation. This means that online users' political participation might be driven by motivated misperception based on political bias or partisanship, more than based on concrete evidence and/or political rationale. The study also found a significant correlation between conservative/liberal orientation and podcast consumption. As more negative/positive emotions arise toward conservative/liberal candidates, so does more participation via online. Given the previous findings, we conjecture 
that people easily seek like-minded people online not only for ideological homogeneity but also for emotional linkage.

\section{Anonymity-preference and political disinhibition}

Then, the question: What if two personal traits - one to belong to the majority, the other to stand up for one's own political beliefs - collide because one's personal network in real life does not harmonize with one's political tendency? Or what people could do if they have to suppress their political opinions due to the fear of isolation or reputational damage despite their having firm opinions on political matters? In those cases, we can conjecture that one might go online for one's political engagement and share ideas as one finds like-minded people using online selectivity.

In response to this question, advanced and tested herein is the selective exposure and FOI thesis, which theorizes that FOI combined with opinion congruency might weaken reallife engagement, yet encourage online engagements and expressions facilitated by online anonymity. Traditional FOI theory focuses on Spiral of Silence where People are more willing to speak out when they believe they belong to the majority, but tend to be silent when they think themselves in a minority in fear of potential isolation. Given that online anonymous platforms enable people to do what they usually would not in the real world (Suler, 2004), we can posit that anonymity can free people from potential fear occasioned by active political engagement and expression.

Anonymity refers to a state in which a person is non-identifiable (Marx, 1999). Anonymous conversation is one of the unique elements that online platform can offer in contrast to traditional media or real-life setting (Samuel, 2004). The role of anonymity has been evaluated as two-edged sword (Johnson, 2003) as the use of monikers and pseudonyms potentially equalizes participation and frees individuals from possible reputational damages. Also, anonymity lowers inhibitions and encourages antisocial behaviour online such as 
flaming and trolling (Soon \& Soh, 2014). In political context, anonymity value is based on availability of alter ego whereby one can build a hidden and virtual identity to possibly protect one's real identity from potential threat of real-life sanctions or penalties imposed on minority opinions on controversial issues. Anonymity helps users to relieve psychological discomfort and self-monitoring efforts when they post comments or express their opinions for fear of being criticized, losing face, or creating negative impressions in social media use.

According to Neuwirth et al. (2007) sanctions as well as isolation tend to cause FOI. Thus, we believe FOI could be overcome by online communication as people do not have to use their real names. In real life, people think they can endanger their reputations if they belong to the minority opinion or are perceived by others as politically incorrect. In this regard, online anonymity has been found to decrease one's inhibition and to increase selfdisclosure (Bailenson, Yee, Merget, \& Schroeder, 2006). While many people expect anonymity to decrease the quality of the content or help spread rumors by unproven identity online (Soon \& Soh, 2014), interestingly enough, anonymity does not necessarily have a negative effect on the discussion quality, yet helps people to give opinions about controversial issue (Berg, 2016; Cho \& Kwon, 2015). Papacharissi (2004) have noted that no real-life encounters can facilitate heated discussion, therefore enable democratic emancipation through disagreement and anarchy. In this sense, one might highly the role of anonymity as it contributes to the generation of democratic conversations.

\section{Anonymous use of social media in political context}

Moreover, it was indicated that anonymity relates to deindividualization, therefore prompts inter-group antagonism and selective behaviors based on one's own partisanship and group-interest (Hiltz, Turoff, \& Johnson, 1989). To be specific, the effect of using pen names (a form of anonymity) in a conference tends to produce an individual's decision making in accordance with a group's subculture. Subjects appeared to change their attitude to follow a 
group-decision rather than disagreeing with it. Therefore, applying this finding into the context of political conversation, we can conjecture that anonymous conversations might strengthen group identification and inter-group antagonism thereby serve an individual's “opinion-congruency seeking” with like-minded people.

Social media becomes the most effective political vehicle nowadays, also many users tend to use the anonymous feature of social media platforms when it comes to political conversations and engagement for various reasons. First, the anonymity feature often becomes a determinant factor to the nature of social media platform such that Twitter is more of anonymous use and engagement than that of Facebook or LinkedIn that directly connect to one's personal and/or professional network. Twitter, unlike Facebook, offers different relationships among users based on its high level of anonymity. In Twitter, people tend to feel lesser pressure than in Facebook to post about themselves to find 'friends' but they focus on the topic or content they want to say and/or follow (Huberman, Romero, \& Wang, 2009; Panek, Nardis, \& Konrath, 2013). This reduction of social pressure owing to anonymity may relate to increasing popularity of Twitter in Japan whose culture highly merits anonymity online where people can be open and deindividualized in the presence of others (Peary, Shaw, \& Takeuchi, 2012).

In contrast, Facebook has long been considered as a real-identity based platform as Facebook use encourages and eases people to widen their personal/professional relationship with other users (boyd \& Ellison, 2007). However, even in Facebook, social pressure with FOI tends to be involved in the course of self-expression and representation online. Some research found that people often tend to regret their Facebook postings especially in the context of sensitive topics. With respect to the domain of computer-mediated communication, shyness is a particular psychology that might hinder engagement in the online forums for social interactions (Orr et al, 2009). Therefore, it is indicated that even real-name based 
Facebook users feel uncomfortable with expressing their ideas under their real-names (Wang et al., 2011) and to protect one's own reputation and mitigate the loss of face via being evaluated or misjudged by others, people might want to prefer pen-names or fake-IDs.

We also note that online political groups are different as online group membership is more fluid as members of the group enjoyed multiple or false identities via utility of anonymous features online (Kolko \& Reid, 1998). It is also indicated that people feel more comfortable discussing politics online than in person with more of one's own "true selves." (Fitzsimmons, 2002 cited in Conroy, Feezell, \& Guerrero, 2012). Now, in South Korean and other East Asian countries such as Japan, anonymous and politically-selective political forums are very active (Shim, 2015), not only that, major portal sites that aggregate a massive news content also provide conversation thread where people can share their comments and engage with each other to show their political supports and/or disagreements.

Given all, it is posited that people can express their opinions despite the discrepancy between the majority's and their own, when their desire for opinion-congruency can be achieved by engagement with like-minded people via social media. Therefore, we hypothesize that such attitudinal and behavioral tendencies of FOI combined with characteristics of online media will amplify an individual's political consumption and participation online such that FOI, opinion congruency, anonymity-preference and online political engagement are associated. Hence, we formulate the following hypotheses:

H1) FOI will be positively associated with a) opinion congruency and b) anonymitypreference via online.

H2) People who seek opinion congruency will predict a) anonymity-preference via online and b) SMPE.

H3) Anonymity-preference via online will predict social media use for SMPE. 
H4) Anonymity-preference via online will mediate a) FOI and b) a desire for opinion congruency and SMPE.

\section{Social media mobilization and real-life political engagement}

In this regard, examining the influences of anonymity-preference FOI, and opinion congruency for SMPE, begs another question: will increased levels of SMPE lead to political engagement in real-life settings? For instance, the 2017 presidential election in Korea saw such a phenomenon: Perceived and observed effects of the rise in political engagement via Facebook and Twitter resulted in historically-massive offline protests (Lim, 2016). In this paper, we further investigate whether active online opinion-seeking and interaction lead to offline political participation.

A number of theoretical frameworks and pertinent studies have shed light on the topic. First, merely creating and maintaining a social media account is not sufficient (Skoric \& Zhu, 2016; Theocharis \& Lowe, 2016). One's active online participation is a significant factor for offline participation (T. T. C. Lin \& Chiang, 2017). While online vs. offline participation derive from different kinds of social capital and have asymmetrical effects (Gil de Zúñiga, Barnidge, \& Scherman, 2017), studies indicate that active engagement in social media sites indeed leads to offline political participation (Gil de Zúñiga \& Liu, 2017; Lilleker \& Koc-Michalska, 2017; J.-H. Lin, 2016; Skoric \& Zhu, 2016).

Efficacy of using social media for political purposes may also be a factor (Park, 2015). Namely, social media can be useful for conveniently finding and engaging with political views congruent to one's own. Liu and Fahmy (2011) expanded upon the spiral of silence theory and found that increased tendencies to speak out online leads to an increased likelihood of speaking out in real settings, and vice versa - their findings suggested that the congruency between the individual's opinions and the perceived public opinion predicts the 
individual's inclinations to speak out offline. (We find that participation in online political groups is strongly correlated with offline political participation, as a potential function of engaging members online (Conroy et al., 2012) Put conversely, McGregor and Mourão (2017) found that disagreement with political content on social media led to political disengagement. Demographic characteristics such as age (J.-H. Lin, 2016) and socioeconomic status (Enjolras, Steen-Johnsen, \& Wollebæk, 2013), may also be a factor in this phenomenon.

Also, expressing one's political views on social media could enable an individual to interact more closely and frequently with like-minded others (Choi \& Cho, 2017), which may result in a sense of kinship and further organizing networks among them. Because these individuals have similar beliefs, their online consolidation could bring common behaviors in real-life settings (Lilleker \& Koc-Michalska, 2017; Skoric \& Zhu, 2016), such as what we were able to observe in the candlelight vigils and political consumerism (e.g., boycotting certain politically-related products) in Korea. Such behaviors also may include donations or volunteer work for candidates (Chang, 2017).

We believe that SMPE could be a key element for those seeking opinion-congruency in their political engagement process. That is, these individuals actively utilize the accessibility and interactivity of social media to express themselves and look for opinion congruency, efforts which then are expanded to political engagement in real settings (Gil de Zúñiga \& Liu, 2017; Wang, 2007). In this paper, we operationalized levels and types of political engagement using measures adopted and modified from Gil de Zúñiga, Copeland, and Bimber (2014) and Gil de Zúñiga et al. (2012). Considering the rapid rise in social media consumption (T. T. C. Lin \& Chiang, 2017), this link between SMPE and offline political engagement is arguably an essential component for the success of political campaigns. Therefore, we posit the following hypotheses: 
H5) SMPE will predict offline political engagement.

H6) SMPE will mediate a desire for opinion congruency and offline political engagement.

\section{Method}

\section{Procedure}

A web-based survey was conducted to answer proposed research questions and test hypotheses. The survey was administered by the Korean panel of Macromill Embrain Co., a leading research firm. The survey was conducted from January to February 2017. A total of 1107 respondents participated in the survey. The probability quota sampling was designed based on Korean population statistics (Ministry of the Interior, 2017, July). Participants from the general population were given credit according to the individual reward policy of the company. The number comprised $47.8 \%$ female, $52.8 \%$ male. Average age of participants was 40.75 . We also exclude "less than 20 " and "more than 60 " age brackets as our study focuses on the population of online users in the political context: 228 were in the 20-29 bracket (20.6\%), 280 in the $30-39$ bracket, (23.4\%), 275 in the $40-49$ bracket $(24.7 \%), 315$ in the 50-59 bracket (28.5\%). Participants' age- and gender-distribution was close to the regional population representation designed by our quota sampling. Compared to the statistics (excluding more than 60 age bracket), our sample is fewer in $20-29(-0.4 \%), 30-39(-0.6 \%)$, $40-49(-3.3 \%)$ and more $50-59(+1.5 \%)$. Given that the Internet use is saturated among the younger generations but not among the older, ${ }^{1}$ this distribution is acceptable.

\section{Measures}

Most survey items were adapted from pre-validated research work, so as to increase

\footnotetext{
${ }^{1}$ https://www.statista.com/statistics/348188/daily-internet-usage-age-group-south-korea/
} 
the construct validity. For all measures, 5 point Likert scales were used $(1=$ strongly agree, 3 $=$ neither agree nor disagree, $5=$ strongly disagree) except political engagement and SMPE. The survey items are presented in Appendix 1.

Offline Political engagement. A composite index of political engagement was created by adding a total of five items measuring the frequency of respondents' political engagement behavior. The items were borrowed from previous research on political and civic engagement and revised for the purpose of our research (Gil de Zúñiga et al, 2012; Gil de Zúñiga et al., 2014). Respondents were asked to rate on a six-point scale $(0=$ never, $1=1$ to $5,2=6$ to $10,3=11$ to $15,4=16$ to $20,5=$ more than 20 times during the past year) how often they used social media for the following activities: "participation in political events for a cause or charity", "donating money to political parties or politicians" and the like $(\alpha=.87$, range $=1$ to $6, M=1.49, S D=0.75)$.

Social media use for political engagement (SMPE). Based on online political participation scale of Gil de Zúñiga et al. (2012), we created six new items to measure SMPE. Respondents were asked to rate on a 10-point scale how often they used social media for the following activities: "I have 'followed' or 'friended' a politician or a political party on social media sites such as Facebook or Twitter," and "I have 'liked' the contents about political and social issues on social media sites such as Facebook or Twitter" and other four items $(\alpha=.90$, range $=1$ to $6, M=1.69, S D=0.92$ ).

Fear of isolation (FOI). To measure FOI, we borrowed three items from Kim, 2012. The items include "I worry about being negatively evaluated when others disagree with me," "I tend to let the other person win an argument even when I know I am right," and "If my political opinion were to become widely known around your workplace, I am very concerned that people would avoid me or act differently towards me." $(\alpha=.64, M=2.82, S D=0.47)$. 
Opinion congruency. To measure the extent to which people want to be congruent with others, opinion leaders of the society, we modified four items from S.-H. Kim (2012). The items include "I would like for my opinion to be congruent with the general publics' opinions," "I would like for my opinion to be congruent with opinion leaders' opinions," and "I would like my opinion to be congruent with my family members' opinions." $(\alpha=.85, M=$ $3.43, S D=0.49)$.

Anonymity-preference. We developed four measurement items to gauge perceived anonymity-preference. The items include "During anonymous online conversation via social media or online news site, I feel less constrained to talk about certain things than in conversations where I can be identified," "Anonymous online platforms enable me to support my favorite politicians on political news websites," "With anonymity online, I can argue with someone with different opinions without reservations, in comparison to in the offline setting," and "Anonymous online platforms enable me to engage in political discussions." $(\alpha=.89, M$ $=3.05, S D=0.72$ ).

\section{Results}

To explore relationships between three key variables of voters' political psychology opinion congruency, anonymity-preference and fear of isolation and social media user for political engagement and subsequent offline political engagement, we performed a path analysis $(\mathrm{N}=1107)$. A path analysis via this structural equation modeling approach is useful as it evaluates the global model fit as well as statistical validity of each hypothesized path in the model. All the factors in the model were composite variables.

Data were analyzed with the AMOS 23 software program, with a covariance-based approach, using maximum-likelihood estimation. We assessed model fit using multiple goodness-of-fit indices. First, chi-square statistics were insignificant at $p<0.01(\chi 2(4)=$ $2.557, p=.037$ ) and indicated that the fit of data with the hypothesized model was adequate. 
Other model fit indices such as CFI, TLI, and RMSEA show an acceptable fit for our research model: $\mathrm{CFI}=0.995, \mathrm{TLI}=0.986$, and RMSEA $=.004$. Therefore, these goodness-of-fit indices indicate the final model fits data well.

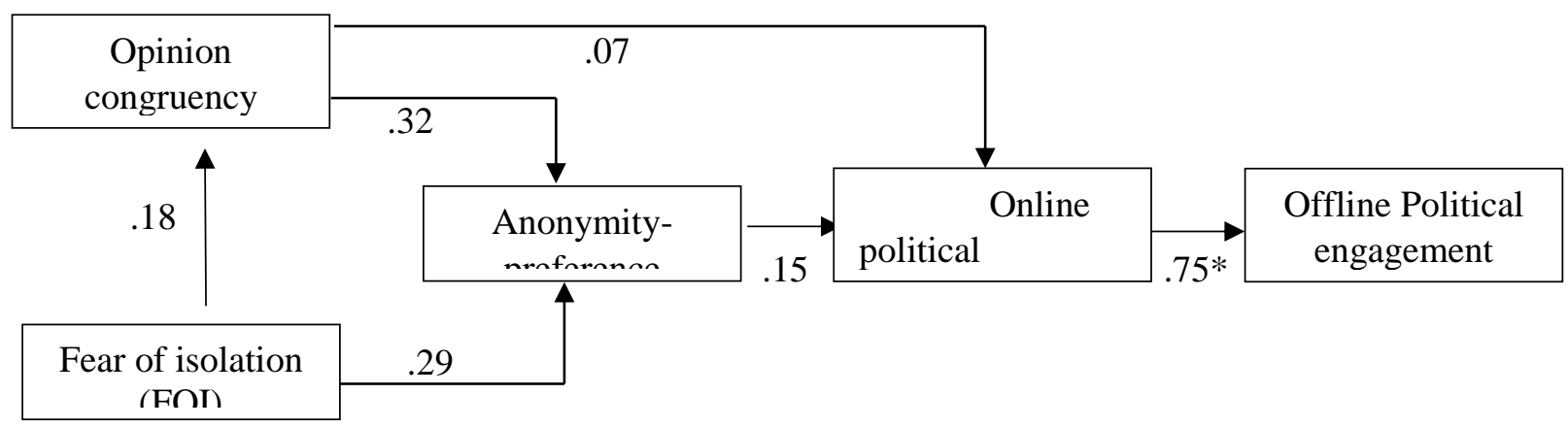

Figure 1. Research Model and Hypotheses

\section{Hypotheses testing}

Regarding relationships observed among endogenous variables, research results supported five direct paths and one correlated path. H1a and $\mathrm{H} 1 \mathrm{~b}$ posited that fear of isolation will be associated positively with opinion congruency (H1a) and anonymity-preference via online (H1b). The path between opinion congruency and fear of isolation was significant $(\beta$ $=.175, p<.001)$. Hence, H1a is supported. The path between fear of isolation and anonymity-preference via online also was significant $(\beta=.290, p<.001)$. Hence data confirmed H1b.

$\mathrm{H} 2 \mathrm{a}$ and $\mathrm{H} 2 \mathrm{~b}$ suggested the effect of opinion congruency on anonymity-preference via online (H2a) and social media use for political engagement (SMPE) (H2b). Anonymitypreference $(\beta=.319, p<.001)$ and SMPE $(\beta=.070, p<0.05)$ both associated positively with opinion congruency, which supported $\mathrm{H} 2 \mathrm{a}$ and $\mathrm{H} 2 \mathrm{~b}$.

As predicted in $\mathrm{H} 3$, anonymity-preference had a positive relationship with $\operatorname{SMPE}(\beta$ $=.150, p<.001)$, thus H3 was supported. Regarding H5, SMPE $(\beta=.748, p<.001)$ was associated positively with political engagement, therefore, H5 was supported. 


\section{Mediation analysis}

$\mathrm{H} 4 \mathrm{a}$ and $\mathrm{H} 4 \mathrm{~b}$ and $\mathrm{H} 6$ posited mediating effect of key traits of social media such as anonymity-preference and SMPE. The indirect effects of opinion congruency on SMPE via anonymity-preference (H4) and on political engagement via SMPE (H6) were examined using an approach proposed by Baron and Kenny (1986), and the significance of the indirect effects was examined using bootstrapping techniques. As suggested by Preacher and Hayes (2008), 5000 bootstrap samples were computed and a bias-corrected $90 \%$ confidence interval (CI) calculated. H4 examined whether anonymity-preference would connect a) FOI with SMPE and b) opinion congruency with SMPE. The indirect effect of FOI on SMPE was significant $(\beta$ [Bootstrap 95\% CI] $=.044[.018, .067], p<.005)$. Also, the indirect effect of opinion congruency on SMPE via anonymity-preference was significant ( $\beta$ [Bootstrap 95\% $\mathrm{CI}]=.049[.021, .073], p<.005)$. Hence, H4a and H4b were all supported.

H6 suggested that opinion congruency would be mediated by SMPE to create political engagement. The indirect effect of opinion congruency on political engagement via SMPE was significant $(\beta$ Bootstrap 95\% CI] $=.088[.039, .15], p<.005)$. Hence, H6 was supported.

\section{Discussion}

This study examined the implications of social media in political contexts, namely elections and political campaigns. Previous work on the topic focused on the value of social media as a new tool for political mobilization in terms of the "agenda setting/framing" effects of mainstream media, or lack thereof (Berger, 2010; Enjolras et al., 2013; Jensen, 2017; Jowett \& O'Donnell, 2012). Therefore, the emphasis has been on political organizations and how they can utilize social media to replace and exceed the capabilities of traditional media for dissemination of information, interactivity and fostering participation (Wang \& Yue, 2016; Xiaodong \& Li, 2016; Theocharis \& Lowe, 2016). 
On the other hand, this paper highlights perspectives of the political consumer (or voter) who may not necessarily be active mobilizers at first. By developing the concept, fear of isolation (FOI), in the offline setting as to how it may relate to use of social media, we found that social media are significantly valuable for such voters because virtual platforms enable an outlet for political engagement. Further, this enhanced use of social media for political engagement (SMPE) among the public draws like-minded individuals closer in the virtual realm and reversely influences how a politician is portrayed. Therefore, this study contributes to our knowledge by enlightening us about how and why social media audiences may become information producers, content creators and agenda setters that drive the bandwagon effect on their own. Under the traditional framework, bandwagon effect over those who have fear of isolation is been driven by the major news outlets' agenda-setting effect; now in the advent of social media, FOI rather paradoxically indicates suppressed political desire for engagement and expression regarding controversial political topics, and further leads to active participation via anonymous social media outlets.

A key component of this study is the newfound aspect of FOI in the online context. With $\mathrm{H} 1$ and $\mathrm{H} 2$, we found a correlation among FOI, opinion congruency and anonymity preference. Existing studies on FOI have focused on the influences of traditional media, whose perceived dominant opinions generate a spiral of silence effect. However, this study uncovered a possible dual effect of FOI — we explored the underlying correlation between FOI and the motivation for the sense of belonging (seeking opinion congruency). Such a desire, therefore, may lead FOI in real life to a willingness to express oneself.

Another key finding of this study is that anonymity-preference in the online setting predicted the use of social media for political engagement (SMPE). With an increased motivation for expressing oneself, FOI individuals may seek anonymous conditions (due to the very fear of being isolated), making social media platforms a staple for their engagement. 
Yun and Park (2011) also explored the effect of anonymity and found that an association exists between the climate of public opinion and willingness to speak out, but the study fails to confirm anonymity's influence on the willingness to speak out. Moreover, although the Yon et al. study found that online might mitigate FOI through anonymity in comparison to offline settings, there was no evidence regarding the direct effect of anonymity on the individual's willingness to speak out. In this light, this study explored the linkage among FOI, anonymity and the willingness to express oneself by considering a political psychology factor: seeking opinion congruency. In other words, anonymity and reduced FOI by themselves do not sufficiently yield active participation, but are only contextually helpful for those who have strong will to participate yet still feel suppressed in expressing themselves.

Thus, this study enables a better understanding of the value of social media for political discourse. Online traits such as selectivity, anonymity and reduced FOI are strongly preferred by those who have a strong desire for political engagement, therefore lead to the rise of a specific type of active and collective, yet virtually-oriented engagement (SMPE). We hope that this research sheds light on practical implications for how political campaigns could successfully approach the social media demographic.

Finally, we found increased SMPE also allows for audience-centered political mobilization. With H5 and H6, we found that SMPE predicted political engagement and mediated the desire for opinion congruency and offline engagement. We also saw a significant overlap between online and offline engagement. We believe that this points us to a phenomenon where the individual's virtual identity gradually expands toward his/her real identity. This means that active, participatory virtual identities of those who were active online but hesitant to engage in the real world, helps these individuals to participate more actively in offline settings as well. Aided by features of social media such as anonymity, accessibility and interactivity, audiences use the platform as a means to find politically like- 
minded others. As noted above, virtual identities associated with these online interactions turn into real-life identities, in turn increasing offline engagement among them.

In this sense, we believe our study contributes to the relationship between offline and online political contexts. In those contexts, extensive scholarly interest has been shown in gauging the political value of new media compared to traditional media. That is, in what ways could online media outlets benefit users? However, not much research provides insights into online uniqueness and its political value such as interactivity and anonymity which inter alia could facilitate freedom of speech, especially for those who are (or at least feel) pressured in the offline setting. Therefore, our study could add more knowledge regarding political cynicism, lack of interest, and apathy (Gil de Zúñiga et al., 2009) and how such elements negative to political engagement could be dissolved by online alternatives.

This finding about SMPE leading to offline mobilization highlights the need for political campaign practitioners to attend closely to highly-engaged individuals on social media even if they are not visible in real settings. Although these individuals might not seem so active from a conventional political-campaigning viewpoint, they are potentially a strong force with growing behavioral intentions for offline participation. The highly-active and engaged protesters of the Park Geun-hye impeachment and the enthusiastic supporters of Moon Jae-in are cases in point. With Moon in particular, his supporters displayed a strong online presence, which arguably allowed him to be the overwhelming leader in the presidential elections following President Park's impeachment (Campbell, 2017; Chung, 2017). His popularity on social media contrasted with the negative coverage of mainstream media (Chang, 2017; Won, 2017). From a traditional viewpoint, the mainstream media dismissal of Moon casts him an underdog. In this 2017 election however, high levels of political engagement among social media users spilled over to audience-centered mobilization and voting leading to a Moon landslide win. Therefore, we posit significant 
implications for politics in the social media age. Even political underdogs or minorities can cause their voices to be heard on social media, and could go beyond the online arena when the enhanced SMPE shifts into offline political engagement.

Our study also begs an interesting scholarly question regarding political bias, selectivity and partisanship in the political use of social media. Based on our findings, it is indicated that cynicism toward traditional media relates to even more-severe partisanship online. What difference is there between traditional partisan media and the online community? Traditional media partisanship might be perceived as commercially-oriented and a mode of top-to-bottom doctrine from journalists to laypeople, whereas online creates twoway communication thus a user-driven bandwagon. And we found that such anonymity significantly facilitates participation and expression without the fear of reputational damage, penalty, or sanctions in the non-online setting.

Seemingly, online and traditional media do not differentiate each other in partisanship, opinion congruency, and bandwagon effect, yet online eases access to the likeminded community. Those who are potentially enthusiastic and their interests therefore function as a bridge between virtual-world and real-world engagement. The convergence of social media across online and offline is predicted by Gil de Zúñiga, et al. (2009) thus: "blog use emerges as an equally important predictor of political engagement in the online domain" (p. 553).

Practitioners should bear in mind the different nature of online and offline in userdriven political culture and the bandwagon-creation process. Those media outlets are converging and seemingly alike in user motivations such as opinion congruency seeking, and online is a testbed or starting point to recruit activists and/or supporters while traditional mass communication is suitable to mass appeal about a political agenda or a candidate. 
In conclusion, this paper explored the underpinnings of political engagement with a new approach that combined various concepts such as FOI, opinion congruency, anonymity, efficacy, and willingness for expression/participation (both online and off) that range from social media features to political psychology. The findings suggest that individuals who are opinionated yet have FOI will seek social media for expression (SMPE), which may expand onto offline engagement and audience-centered mobilization. This study contributes to research and practice alike in that it notes the potential of SMPE and how it can shape (or reshape) elections. Political communication research could benefit from our synthesis of the factors associated with political engagement, and practitioners could look further into how SMPE translates into offline participation and political behavior in real settings.

\section{Limitations and suggestions for future research}

Our study is not without shortcomings. First, we used a survey methodology to examine the theoretical model of FOI relative to the online context. We note that previous studies within the FOI framework have employed various methodologies such as experiment (e.g., Hayes, 2007), time-series observations (e.g., Matthes, 2014) or nation-wide secondary data (e.g., Gearhart \& Zhang, 2015) in testing and measuring the effect of FOI on the spiral of silence. Also, previous studies in computer-mediated communication have employed an experimental approach (e.g., Yun \& Park, 2015) or content analysis (e.g., Reader, 2012) to examine the effect of anonymity. Therefore, we admit that other various methods could be more a more theoretically-valid approach for behavioral studies than relying on participants' self-reports about their behaviors.

Despite the experiment's strengths in looking at the main effect of the variables via manipulation, we point out that experimental methods are not very suitable to look at the overall structure and paths among interested variables. For example, Yun and Park (2011) examined the effect of anonymity via experiment but fail to find the effect on willingness to 
speak. We conjecture that anonymity in the online conversational context has no effect on its own but has some effect in a certain context. Thus, we believe that despite its limitation/s, the survey method enables looking at any point at the effect of an anonymous setting with other individual factors such as FOI or opinion-congruency seeking. More important, the survey method can bring more external validity as we have examined political engagement via social media and real-life engagement. An experimental setting where people express their political opinions might not capture effectively what is happening in participants' real lives.

Second, our sample was collected only in South Korea, so we cannot rule out possible cultural effect on participants' political social media lives. To be specific, the result should be taken with a grain of salt as South Korea is one of the most-developed nations in terms of online technology and social media industry (Akamai, 2016) thus relationships among the interested variable could be inflated under the cultural and media context unique to Korean society. Although Korean society is well-known for having achieved democracy in a peaceful and constitutional way, many Koreans still feel themselves to be under hierarchical pressure and in an undemocratic social or work environment where freedom of speech is restricted by fear of isolation (Han \& Ling, 1998). Also, we should consider the clearly-authoritarian culture prevalent in the Asian context (Zhang, 2012). If other Asian nations would be under political and social environments similar to South Korea's, it would be interesting to see the cultural influence on the suggested model in this study by collecting samples from those. 


\section{References}

Akamai, July 14, 2016. retrieved from

https://www.akamai.com/kr/ko/multimedia/documents/state-of-the-internet/akamai-state-ofthe-internet-q2-2016-connectivity-infographic.pdf

Bailenson, JN, Yee, N, Merget, D, \& Schroeder, R (2006). The effect of behavioral realism and form realism of real-time avatar faces on verbal disclosure, nonverbal disclosure, emotion recognition, and copresence in dyadic interaction. Presence, 15, 359-372.

Bargh, J. A., McKenna, K. Y. A., \& Fitzsimmons, G. M. (2002). Can you see the real me? Activation and expression of the 'true self' on the Internet. Journal of Social Issues, $59,33-48$.

Baum, MA, \& Groeling, T (2008). New media and the polarization of American political discourse. Political Communication, 25(4), 345-365.

Berg, J (2016). The impact of anonymity and issue controversiality on the quality of online discussion. Journal of Information Technology \& Politics, 13(1), 37-51.

Berger, G (2010). Problematizing 'media development' as a bandwagon gets rolling. International Communication Gazette, 72(7), 547-565.

Bobkowski, PS (2015). Sharing the news: Effects of informational utility and opinion leadership on online news sharing. Journalism \& Mass Communication Quarterly, 92(2), 320-345.

boyd, D. M., \& Ellison, N. B. (2007). Social network sites: Definition, history, and Scholarship. Journal of Computer-Mediated Communication, 13(1), 210-230. 
Brundidge, J (2010). Encountering "difference" in the contemporary public sphere: The contribution of the Internet to the heterogeneity of political discussion networks. Journal of Communication, 60(4), 680-700.

Campbell, C (2017, May 9). Moon Jae-in elected South Korea's new president by landslide, Time. Retrieved from http://time.com/4771881/moon-jae-in-president-election-southkorea/

Chang, S (2017, May 23). 'Ten days into Moon administration': Most critical media organization is Chosun Ilbo. Media Today. Retrieved from http://www.mediatoday.co.kr/?mod=news\&act=articleView\&idxno=136993

Chen, CY \& Chang, SL (2017). User-oriented perspective of social media used by campaigns. Telematics \& Informatics, 34(3), 811-820.

Cho, D., \& Kwon, K. H. (2015). The impacts of identity verification and disclosure of social cues on flaming in online user comments. Computers in Human Behavior, 51, 363372.

Choe, SH (2017, May 9). South Korea elects Moon Jae-in, who backs talks with North Korea, as president, The New York Times. Retrieved from https://www.nytimes.com/2017/05/09/world/asia/south-korea-election-president$\underline{\text { moon-jae-in.html? } \mathrm{r}=0}$

Choi, S.Y., \& Cho, Y. (2017). Generating Counter-Public Spheres Through Social Media: Two Social Movements in Neoliberalised South Korea. Javnost-The Public, 24(1), $15-33$.

Chung, J (2017, May 29). President Moon continues on bold SNS path, Korea Times. Retrieved from http://www.hankookilbo.com/v/21710bcf8ba54af9907d3685da50677b 
Coe, K, Tewksbury, D, Bond, BJ, Drogos, KL, Porter, RW, Yahn, A and Zhang, Y (2008), 'Hostile news: Partisan use and perceptions of cable news programming', Journal of Communication, 58(2), 201-219.

Conroy, M., Feezell, J. T., \& Guerrero, M. (2012). Facebook and political engagement: A study of online political group membership and offline political engagement. Computers in Human behavior, 28(5), 1535-1546.

Enjolras, B, Steen-Johnsen, K, \& Wollebæk, D (2013). Social media and mobilization to offline demonstrations: Transcending participatory divides? New Media \& Society, 15(6), 890-908.

Enli, G (2017). Twitter as arena for the authentic outsider: Exploring the social media campaigns of Trump and Clinton in the 2016 US Presidential election. European Journal of Communication, 32(1), 50-61.

Feldman, L (2011). Partisan differences in opinionated news perceptions: A test of the hostile media effect. Political Behavior, 33(3), 407-432.

Gearhart, S, \& Zhang, W (2015). "Was it something I said?" "No, it was something you posted!" A study of the spiral of silence theory in social media contexts. Cyberpsychology, Behavior, and Social Networking, 18(4), 208-213.

Gil de Zúñiga, H, \& Liu, JH (2017). Second Screening Politics in the Social Media Sphere: Advancing Research on Dual Screen Use in Political Communication with Evidence from 20 Countries. Journal of Broadcasting \& Electronic Media, 61(2), 193-219.

Gil de Zúñiga, H, Barnidge, M, \& Scherman, A (2017). Social media social capital, offline social capital, and citizenship: Exploring asymmetrical social capital effects. Political Communication, 34(1), 44-68. 
Gil de Zúñiga, H, Copeland, L, \& Bimber, B (2013). Political consumerism: Civic engagement and the social media connection. New Media \& Society, 16(3), 488-506.

Gil de Zúñiga, H, Jung, N, \& Valenzuela, S (2012). Social media use for news and individuals' social capital, civic engagement and political participation. Journal of Computer-Mediated Communication, 17(3), 319-336.

Gil de Zúñiga, H, Puig-i-Abril, E, \& Rojas, H (2009). Weblogs, traditional sources online and political participation: An assessment of how the Internet is changing the political environment. New media \& society, 11(4), 553-574.

Groeling, T. (2008), 'Who’s the fairest of them all? An empirical test for partisan bias on ABC, CBS, NBC, and Fox News', Presidential Studies Quarterly, 38(4). 628-653.

Hahn, KS, Ryu, S, \& Park, S (2015). Fragmentation in the Twitter Following of News Outlets: The Representation of South Korean Users' Ideological and Generational Cleavage. Journalism \& Mass Communication Quarterly, 92(1), 56-76.

Han, J, \& Ling, LHM (1998). Authoritarianism in the hypermasculinized state: Hybridity, patriarchy, and capitalism in Korea. International Studies Quarterly, 42(1), 53-78.

Hanson, G, Haridakis, PM, Cunningham, AW, Sharma, R \& Ponder, JD (2010). The 2008 Presidential Campaign: Political Cynicism in the Age of Facebook, MySpace, and YouTube, Mass Communication and Society, 13(5), 584-607.

Hayes, AF (2007). Exploring the Forms of Self-Censorship: On the Spiral of Silence and the Use of Opinion Expression Avoidance Strategies. Journal of Communication, 57, $785-802$. 
Hayes, AF, Matthes, J, \& Eveland, WP (2011). Stimulating the quasi-statistical organ: Fear of social isolation motivates the quest for knowledge of the opinion climate. Communication Research, 40(4), 439-462.

Hiltz, S. R., Turoff, M., \& Johnson, K. (1989). Experiments in group decision making, 3: Disinhibition, deindividuation, and group process in pen name and real name computer conferences. Decision Support Systems, 5(2), 217-232.

Huberman, B. A., Romero, D. M., \& Wang, F. (2009). Social networks that matter: Twitter under the microscope. First Monday, 14.

Hughes, D. J., Rowe, M., Batey, M., \& Lee, A. (2012). A tale of two sites: Twitter vs. Facebook and the personality predictors of social media usage. Computers in Human Behavior, 28(2), 561-569.

Iyengar, S, \& Hahn, KS (2009). Red media, blue media: Evidence of ideological selectivity in media use. Journal of Communication, 59, 19-39.

Jensen, MJ (2017). Social media and political campaigning. International Journal of Press/Politics, 22(1), 23-42.

Johnson, D. G. (2003). Reflections on campaign politics, the internet, and ethics. In D. M. Anderson \& M. Cornfield (Eds.), The civic web: Online politics and democratic values (pp. 9-18). Lanham, MA: Rowman \& Littlefield.

Jowett, G, \& O'Donnell, V (2012). Propaganda and persuasion (5th ed.). Thousand Oaks, CA: Sage.

Kaid, LL (2002). Political advertising and information seeking: Comparing exposure via traditional and Internet channels. Journal of Advertising, 31(1), 27-35. 
Kim, C, \& Santiago, R (2005). Construction of e-learning environments in South Korea. Educational Technology, Research and Development, 53(4), 108-115.

Kim, D (2017, May 11). [Moon Jae-in Blue House] Press Secretary Yoon Young-chan... SNS director who led "Moon Jae-in First street", Focus News. Retrieved from http://www.focus.kr/view.php?key=2017051100094458630

Kim, SH, Kim, H, \& Oh, SH (2014). Talking About Genetically Modified (GM) Foods in South Korea: The Role of the Internet in the Spiral of Silence Process. Mass Communication and Society, 17(5), 713-732.

Kim, Y, Kim, Y, \& Wang, Y (2016). Selective exposure to podcast and political participation: the mediating role of emotions. International Journal of Mobile Communications, 14(2), 133-148.

Kolko, B., \& Reid, E. (1998). Fragmentation: Problems in On-Line. Cybersociety 2.0: Revisiting Computer-Mediated Community and Technology, 2, 212.

Kreiss, D (2016). Seizing the moment: The presidential campaigns' use of Twitter during the 2012 electoral cycle. New Media \& Society, 18(8), 1473-1490.

Lampel, J., \& Bhalla, A. (2007). The role of status seeking in online communities: Giving the gift of experience. Journal of Computer-Mediated Communication, 12(2), 434-455.

Lee, E.J, \& Shin, SY (2014). When the medium is the message: How transportability moderates the effects of politicians' Twitter communication. Communication Research, 41(8), 1088-1110.

Lilleker, DG, \& Koc-Michalska, K (2017). What drives political participation? Motivations and mobilizations in a digital age. Political Communication, 34(1), 21-43. 
Lim, G (2016, December 3). 6th Weekend Candlelight Vigil Sets New Record: Organizers State '2.12 Million', Yonhap News. Retrieved from http://www.yonhapnews.co.kr/bulletin/2016/12/03/0200000000AKR2016120305850 0004.HTML

Lin, JH (2016). Differential gains in SNSs: Effects of active vs. passive Facebook political participation on offline political participation and voting behavior among first-time and experienced voters. Asian Journal of Communication, 26(3), 278-297.

Lin, TTC \& Chiang, YH (2017). Dual Screening: Examining Social Predictors and Impact on Online and Offline Political Participation Among Taiwanese Internet Users. Journal of Broadcasting \& Electronic Media, 61(2), 240-263.

Liu, X \& Fahmy, S (2011). Exploring the spiral of silence in the virtual world: Individuals' willingness to express personal opinions in online versus offline settings. Journal of Media \& Communication Studies, 3(2), 45-47.

MacKinnon, R. (2008). Flatter world and thicker walls? Blogs, censorship and civic discourse in China. Public Choice, 134(1), 31-46.

Marx, G. T. (1999). What's in a name? Some reflections on the sociology of anonymity. The Information Society, 15(2), 99-112. doi:10.1080/019722499128565.

Matthes, J (2014). Observing the "spiral" in the spiral of silence. International Journal of Public Opinion Research, 27(2), 155-176.

McGregor, SC \& Mourão, RR (2017). Second screening Donald Trump: Conditional indirect effects on political participation. Journal of Broadcasting \& Electronic Media, 61(2), 264-290. 
McKinnon, M, Semmens, D, Moon, B, Amarasekara, I, \& Bolliet, L (2016). Science, Twitter and election campaigns: Tracking \#auspol in the Australian federal elections. Journal of Science Communication, 15(6), 1-22.

Meyer, HK, Marchionni, D, \& Thorson, E (2010). The journalist behind the news: credibility of straight, collaborative, opinionated, and blogged "news". American Behavioral Scientist, 54(2), 100-119.

Ministry of the Interior (2015, July), Statistics of resident registration, available at http://rcps.egov.go.kr:8081/jsp/stat/ppl_stat_jf.jsp

Morin, R (2016, November 12). Trump says social media was key to victory, Politico. Retrieved from http://www.politico.com/story/2016/11/donald-trump-social-media231285

Neuwirth, K, Frederick, E, \& Mayo, C (2007). The spiral of silence and fear of isolation. Journal of Communication, 57(2007), 450-468.

Noelle-Neumann, E (1974). The spiral of silence: A theory of public opinion. Journal of Communication, 24(1), 24-51.

Oh, D (2017, March 16). [Candidate Investigation: Verdict] Moon Jae-in campaign re-hired director responsible for 'SNS task force', Newstapa. Retrieved from

\section{http://newstapa.org/38785}

Oh. S. (2016) Korean journalism tends to extensively use anonymous sources. Retrieved from http://danbinews.blog.me/220751326470

Orr, E. S., Sisic, M., Ross, C., Simmering, M. G., Arseneault, J. M., \& Orr, R. R. (2009). The influence of shyness on the use of Facebook in an undergraduate sample. Cyberpsychology \& Behavior, 12(3), 337-340. 
Ott, B.L. (2017). The age of Twitter: Donald J. Trump and the politics of debasement. Critical Studies in Media Communication, 34(1), 59-68.

Panek, E. T., Nardis, Y., \& Konrath, S. (2013). Mirror or Megaphone?: How relationships between narcissism and social networking site use differ on Facebook and Twitter. Computers in Human Behavior, 29(5), 2004-2012.

Papacharissi, Z (2004). Democracy online: Civility, politeness, and the democratic potential of online political discussion groups. New media \& society, 6(2), 259-283.

Park, C (2015). Pathways to expressive and collective participation: Usage patterns, political efficacy, and political participation in social networking sites. Journal of Broadcasting \& Electronic Media, 59(4), 698-716.

Peary, B. D., Shaw, R., \& Takeuchi, Y. (2012). Utilization of social media in the east Japan earthquake and tsunami and its effectiveness. Journal of Natural Disaster Science, 34(1), 3-18.

Pinkleton, BE, Austin, EW, Zhou, Y, Willoughby, JF, \& Reiser, M (2012). Perceptions of news media, external efficacy, and public affairs apathy in political decision making and disaffection. Journalism \& Mass Communication Quarterly, 89(1), 23-39.

Porten-Cheé, P, \& Eilders, C (2015). Spiral of silence online: How online communication affects opinion climate perception and opinion expression regarding the climate change debate. Studies in Communication Sciences, 15(2015), 143-150.

Pramuk, J (2016, November 9). Trump spent about half of what Clinton did on his way to the presidency, CNBC. Retrieved from http://www.cnbc.com/2016/11/09/trump-spentabout-half-of-what-clinton-did-on-his-way-to-the-presidency.html 
Reader, B (2012). Free press vs. free speech? The rhetoric of "civility" in regard to anonymous online comments. Journalism \& Mass Communication Quarterly, 89(3), 495-513.

Samuel, A. W. (2004). Hacktivism and the future of political participation (Doctoral dissertation). Harvard University, Cambridge, MA.

Shim, K. (2015). Hardcore Subcultures for Law-Abiding Citizens and Online Nationalism: Case Study on the Korean Internet Community ILBE Jeojangso. Panorama: Insights into Asian and European Affairs, 2015, 165.

Skoric, M.M., \& Zhu, Q (2016). Social media and offline political participation: Uncovering the paths from digital to physical. International Journal of Public Opinion Research, $28(3), 415-427$.

Soon, C., \& Soh, Y. D. (2014). Engagement@ Web 2.0 between the government and citizens in Singapore: Dialogic communication on Facebook? Asian Journal of Communication, 24(1), 42-59.

Suler, J (2005). The online disinhibition effect. International Journal of Applied Psychoanalytic Studies, 2(2), 184-188.

Tewksbury, D, Hals, ML, \& Bibart, A (2008). The efficacy of news browsing: The relationship of news consumption style to social and political efficacy. Journalism \& Mass Communication Quarterly, 85(2), 257-272.

Theocharis, Y, T, \& Lowe, W (2016). Does Facebook increase political participation? Evidence from a field experiment. Information, Communication \& Society, 19(10), 1465-1486. 
Tsfati, Y (2010). Online news exposure and trust in the mainstream media: Exploring possible associations. American Behavioral Scientist, 54(1), 22-42.

Udris, R. (2014). Cyberbullying among high school students in Japan: Development and validation of the Online Disinhibition Scale. Computers in Human Behavior, 41, 253261.

Vargo, CJ, Guo, L, McCombs, M, \& Shaw, DL (2014). Network issue agendas on Twitter during the 2012 U.S. Presidential Election. Journal of Communication, 64(2), 296316.

Wang, D, \& Yue, C (2016). Research on the usage of social media in Taiwan region's political campaigns and elections. Intercultural Communication Studies, 25(3), 232247.

Wang, S. I. (2007). Political use of the Internet, political attitudes and political participation. Asian Journal of Communication, 17(4), 381-395.

Wang, Y., Norcie, G., Komanduri, S., Acquisti, A., Leon, P. G., \& Cranor, L. F. (2011, July). I regretted the minute I pressed share: A qualitative study of regrets on Facebook. In Proceedings of the seventh symposium on usable privacy and security (p. 10). ACM.

Won, S. (2017, May 13). Chosun Ilbo criticized Moon with two editorials, Huffington Post Korea. Retrieved from http://www.huffingtonpost.kr/2017/05/13/story_n_16588338.html

Xiaodong, Y, \& Li, L (2016). Will the Spiral of Silence Spin on Social Networking Sites? An Experiment on Opinion Climate, Fear of Isolation and Outspokenness. China Media Research, 12(1), 79-87. 
Yamamoto, M, \& Kushin, MJ (2014). More harm than good? Online media use and political disaffection among college students in the 2008 election. Journal of ComputerMediated Communication, 19(3), 430-445.

Yun, GW \& Park, SY (2011). Selective posting: Willingness to post a message online. Journal of Computer-Mediated Communication, 16(2011), 201-227.

Zhang, W (2012). The effects of political news use, political discussion and authoritarian orientation on political participation: evidences from Singapore and Taiwan, Asian Journal of Communication, 22(5), 474-492. 


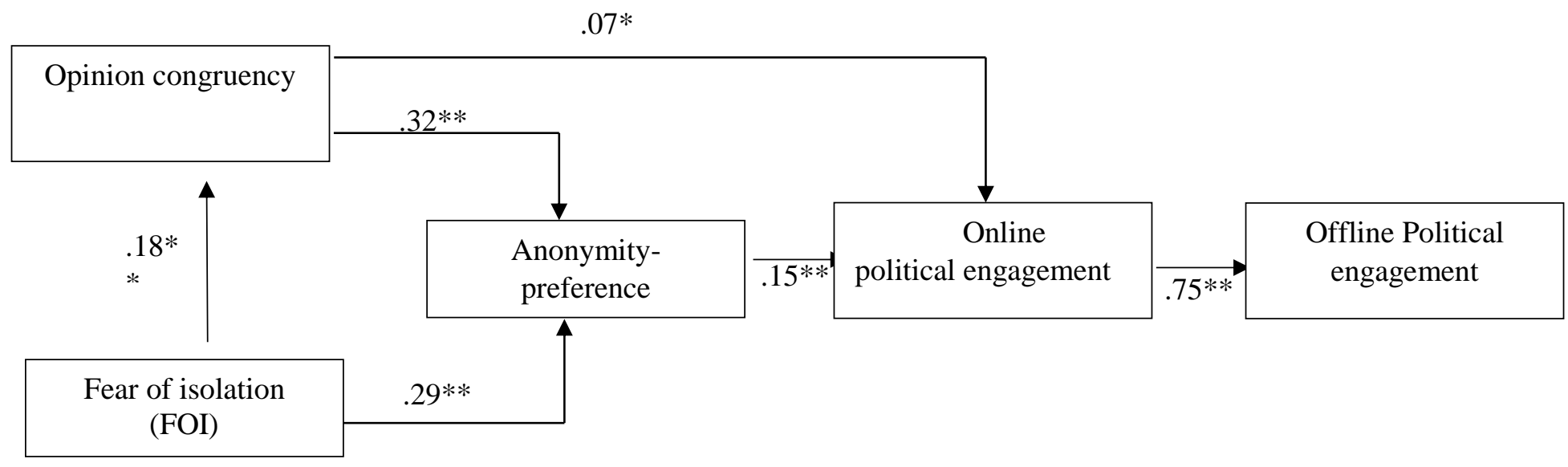

Figure 1. Research Model and Hypotheses

H1) FOI will be positively associated with a) opinion congruency and b) anonymity-efficacy via online.

H2) People who seek opinion congruency will predict a) anonymity-efficacy via online and b) SMPE.

H3) Anonymity-efficacy via online will predict social media use for SMPE.

H4) Anonymity-efficacy via online will mediate a) FOI and b) a desire for opinion congruency and SMPE.

H5) SMPE will predict political engagement.

H6) SMPE will mediate a desire for opinion congruency and political engagement 


\section{Appendix 1}

\section{Fear of isolation (FOI)}

- I worry about being negatively evaluated when others disagree with me.

- I tend to let the other person win an argument even when I know I am right.

- If my political opinion were to become widely known around your workplace, I am very concerned about that people would avoid me or act differently toward me somehow.

\section{Opinion congruency}

- I would like to have congruency between my opinion and general publics' opinions

- I would like to have congruency between my opinion and opinion leaders' opinions

- I would like to have congruency between my opinion and friends' opinions

- I would like to have congruency between my opinion and my family members' opinions

\section{Anonymity-seeking}

- During anonymous online conversation via social media or online news site, I feel less constrained to talk about certain things than identifiable conversation.

- Anonymous online platform enables me to support my favorite politicians on political news website.

- I can argue with someone having different opinion without reserve than offline context thanks to anonymity online.

- Anonymous online platform enables me to engage in political discussion.

\section{Social media use for political expression (SMPE)}

- I have 'followed' or 'friended' a politician or a political party on social media sites such as Facebook or Twitter.

- I have 'liked' the contents about political and social issues on social media sites such as Facebook or Twitter.

- I have expressed my political views or opinions on social media using my profile description or picture.

- I support politicians on social media such as Facebook, Twitter or online news comment thread.

- I have signed an online petition about a local, national, or international issue.

- I have worn or put an online badge, a sticker, or a ribbon on my online profile to express my support for a cause or a charity.

\section{Offline political engagement}

- I have participated in political events for a cause or a charity (e.g., fund raising for Sewohl ferry victims, Candlelight demonstration)

- I have volunteered to help a political party or a politician.

- I have donated money to a political party or a politician.

- I have deliberately purchased certain products or services for political/ethical lenvironmental reasons.

- I have deliberately boycotted certain products or services if the company undermines political/ethical/environmental values. 